\title{
Usefulness assessment of standard measuring instruments installed on sea-going ships to perform energy measurements
}

\author{
Zygmunt Górski, \\ Romuald Cwilewicz, \\ Gdynia Maritime University
}

\begin{abstract}
The presented work is a contribution to discussion on usefulness of application of measurement instrumentation used on sea-going ships for energy measurement and scientific research purposes. Contemporary sea-going ships are equipped as a rule with up-to-date measurement instrumentation usually based on electronic data processing and computer technique. These authors have made many times use of such instruments in their research work. This way it was not necessary to install any special instruments, that significantly reduced measurement cost. In such cases to obtain a sufficient accuracy of measurements constitutes a crucial problem. In this paper was presented an analysis of measurement errors of some operational parameters of ship and its main propulsion system, elaborated within the frame of the KBN research project no. 9 T12D 033 17. Results of the analysis confirm usefulness of the standard measurement instrumentation installed on ships, and its sufficient accuracy.
\end{abstract}

Keywords : ship, standard measurement instrumentation, accuracy of measurements.

\section{INTRODUCTORY COMMENTS}

Contemporary sea-going ships are fitted as a rule with a rich set of control and measuring instruments. Commonly are in use analogous or digital measuring systems as well as those based on computer technique. They serve both for carrying out direct measurements and data processing in the systems for remote and programmed control of ship operation, main propulsion system and auxiliary shipboard devices.

On ships a special high-accuracy measuring instrumentation is also applied. Such instrumentation is installed only for the time of measurements and it does not belong to ship's standard equipment.

Within the frame of the KBN research project no. 9 T12D 03317 some energy measurements were performed on the training-research ship Horyzont II in the period from 23.06.2001 to 14.07.2001. The measurements covered the quantities associated with operation of ship main propulsion system in various service conditions, namely main engine (ME) power output, ship speed, fuel consumption by the main propulsion system. Additionally were measured selected parameters of ME operation, interesting from the point of view of loading state of main propulsion system, e.g. exhaust gas temperature, supercharging air pressure and temperature. Also, some parameters associated with ME operation such as exhaust gas content in various loading states, were investigated. For carrying out the measurements standard measuring instruments installed on the ship as well as special measuring devices installed by the research team, were used.
The investigations were aimed among other at determination of ship propulsion characteristics. To this end the measurements of ship speed, ME power output and its fuel consumption at various rotational speeds and propeller pitch settings, were performed.

Specification of the standard measuring instruments installed on the ship and used for the research in question is as follows :

for the measuring of : propeller pitch setting, rotational speed of ME and its load index - the integrated computer-based system for measuring operational parameters and control of settings of ship's main propulsion system -Wichmatic 2 Propulsion Control System, Graphic System WM 11 G ECR, WM2 12G ECR, WÄRTSILÄ NSD Norway $\mathrm{AS}$, having digital read-out system

for the measuring of ship speed : the SAL R1 U/N 701488C electro-magnetic log of Consilium Marine Co, having digital read-out system

for the measuring of : exhaust gas temperature at outlets from engine cylinders, rotational speed of turbo-blower, exhaust gas temperature before and behind the turbo-blower, supercharging air pressure and temperature, ship draught the integrated computer-based system for measuring and recording operational parameters of ship power plant devices - NORLIGHT Integrated Ship Monitoring and Control, I/O Station A 01 ER, NORIS Tachometer GMBH \& Co.

$>$ for the measuring of ME fuel consumption - a calibrating tank of $11 \mathrm{dm}^{3}$ capacity being an element of the standard equipment of ship power plant, and a stop-watch. 
By making use of the standard measuring instrumentation its usefulness had to be assessed regarding its accessibility and easiness of read-out taking, and measurement accuracy of selected parameters.

The accessibility and easiness of read-out taking is obvious. The standard measuring systems are fitted with easily readable indicators, usually in an analogue or digital form or in the form of messages displayed on a computer monitor.

In the case of investigations of such complex technical objects as ships, indication and measurement accuracy should be considered in a way different from that used in direct metrological measurements. In experimental investigations of complex objects the variability of measured quantity is assumed to be itself a basic source of errors [2]. The difference results from an influence of disturbing factors on the investigated object. Additionally, errors of the measuring method itself (including read-out errors) should by taken into consideration. In Fig.1 is shown the example distribution of measurement results within a sample, location of the mean value of the sample, as well as the range of changes resulting from variability of the object and inaccuracy of the measuring method. In the case of long-lasting measurements (e.g. of fuel consumption or a large number of repetitions) one should also analyze errors resulting e.g. from a change of service conditions during measurement taking. The whole range of values of resultant factors is called the variability measure of results [2].

The errors resulting from the above mentioned sources can be numbered among random ones. As usually assumed, they are normally distributed that makes it possible to state that in accordance with the Gauss law the average from the sample is the most probable value of the resultant factor obtained from multiple measurements :

$$
\overline{\mathrm{z}}_{\mathrm{j}}=\frac{1}{\mathrm{r}} \sum_{\mathrm{j}=1}^{\mathrm{r}} \mathrm{z}_{\mathrm{j}}
$$

where :

$\mathrm{Z}_{\text {. }}$ - a single measurement result $\mathrm{r}$ - number of repetitions of a measurement.

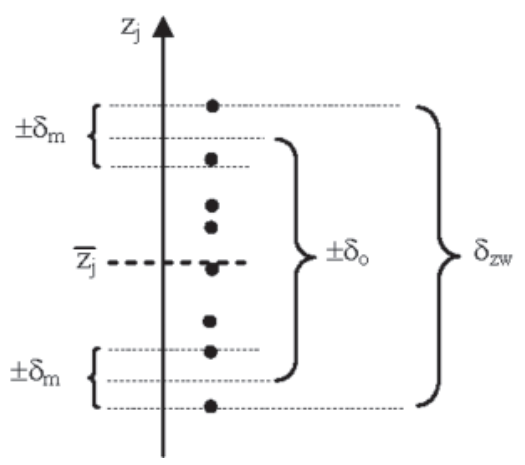

Fig. 1. Diagram of position of variability measures and measurement error for an example sample of results :

$\mathbf{z}_{\mathbf{j}}$ - a single measurement result, $\boldsymbol{\delta}_{\mathrm{m}}$ - measurement method error, $\boldsymbol{\delta}_{\mathbf{0}}$ - variability measure of an object, $\boldsymbol{\delta}_{\mathrm{zw}}$ - variability measure of results, $\overline{\mathbf{z}}_{\mathbf{j}}$ - average value from a sample.

Possible systematic errors resulting from individual features of measuring instruments should be eliminated by introducing some corrections to read-out values on the basis of calibration of the measuring instruments. Also, should be rejected the results deemed to be loaded by rough errors, i.e. those significantly differing from the average from read-out values, resulting from mistakes or other hardly identifiable causes.

The basic variability measure of measurement results is their variance [2]. In the case in question, is of interest the variance of the whole set of results coming from realization of the scope of experiment. For the same number of repetitions, $r$, for every point of the scope the following can be written $[2,3,4]$ :

$$
\sigma^{2}(\mathrm{z})=\frac{1}{\mathrm{~m}(\mathrm{r}-1)} \sum_{\mathrm{u}=1}^{\mathrm{m}} \sum_{\mathrm{j}=1}^{\mathrm{r}}\left(\mathrm{z}_{\mathrm{j}}^{(\mathrm{u})}-\overline{\mathrm{z}}^{(\mathrm{u})}\right)^{2}
$$

where :

$\mathrm{m}$ - number of measurement points

$\mathrm{r}$ - number of repetitions in a measurement point $z_{j}^{(u)}-$ result of a single measurement

$\overline{\mathrm{Z}}^{(\mathrm{u})}-$ average value in a measurement point.

The root-mean-square error of results or standard deviation is equal to the square root of variance [2] :

$\sigma(z)=\sqrt{\sigma^{2}(\mathrm{z})}=\sqrt{\frac{1}{\mathrm{~m}(\mathrm{r}-1)} \sum_{\mathrm{u}=1}^{\mathrm{m}} \sum_{\mathrm{j}=1}^{\mathrm{r}}\left(\mathrm{z}_{\mathrm{j}}^{(\mathrm{u})}-\overline{\mathrm{z}}^{(\mathrm{u})}\right)^{2}}$

The standard deviation of the average, i.e.

the mean standard error of the average

is described by means of the following expression :

$\sigma_{\bar{z}}=\frac{\sigma(z)}{\sqrt{m r}}=\sqrt{\frac{1}{m^{2} r(r-1)} \sum_{u=1}^{m} \sum_{j=1}^{r}\left(z_{j}^{(u)}-\bar{z}^{(u)}\right)^{2}}$

and the relative mean square error, i.e. the variability coefficient of results - by the expression :

$$
\sigma=\frac{\sigma(\mathrm{z})}{\overline{\mathrm{Z}}_{\mathrm{s} \mathrm{r}}^{(\mathrm{u})}} 100 \%
$$

where :

$\overline{\mathrm{Z}}_{\mathrm{sr}}^{(\mathrm{u})}$ - average from a sample of results.

In the case of the direct measurements of the independent quantities $\mathrm{x}_{1}, \mathrm{x}_{2}, \ldots \mathrm{x}_{\mathrm{n}}$, the root- mean-square error is equal to [5]:

$$
\sigma(\mathrm{z})=\sqrt{\sigma^{2}\left(\mathrm{x}_{1}\right)+\sigma^{2}\left(\mathrm{x}_{2}\right)+\ldots+\sigma^{2}\left(\mathrm{x}_{\mathrm{n}}\right)}
$$

whereas the mean square error of the functions of direct measurements of the kind : $z=f\left(x_{1}, x_{2}, \ldots x_{n}\right)$, is equal to [5] :

$$
\sigma(\mathrm{z})=\sqrt{\frac{\left(\frac{\delta \mathrm{f}}{\delta\left(\mathrm{x}_{1}\right)}\right)^{2} \sigma^{2}\left(\mathrm{x}_{1}\right)+\left(\frac{\delta \mathrm{f}}{\delta\left(\mathrm{x}_{2}\right)}\right)^{2} \sigma^{2}\left(\mathrm{x}_{2}\right)+\ldots}{\ldots+\left(\frac{\delta \mathrm{f}}{\delta\left(\mathrm{x}_{\mathrm{n}}\right)}\right)^{2} \sigma^{2}\left(\mathrm{x}_{\mathrm{n}}\right)}}
$$

Discussion on usefulness of the standard measuring instrumentation intended for energy measurements on ships was carried out on the example of measuring the ship speed and ME fuel consumption. Accuracy of measurements and measurement method was assumed an assessing criterion.

The measurements were performed in accordance with a static, determined, multi-factor, rotational and uniform program of the technical experiment, described in [2], which contains 13 measurement points. The measurement accuracy was assessed in compliance with the above presented principle of interpretation and by using the formulae $(2 \div 16)$. 


\section{ACCURACY ASSESSMENT OF SHIP SPEED MEASUREMENTS}

The accuracy assessment of ship speed measurements was performed for the results obtained from two measurement series (no. 2 and 4 according to the same notation as that used in measurement reports from shipboard tests), carried out in similar sea conditions, which are presented in the table below:

\begin{tabular}{|c|c|c|c|}
\hline \multirow{2}{*}{$\begin{array}{c}\text { No. of } \\
\text { measurement }\end{array}$} & \multicolumn{3}{|c|}{ Ship speed v[kn] } \\
\cline { 2 - 4 } & Series no. 2 & Series no. 4 & On average \\
\hline $\mathrm{u}$ & $\mathrm{v}_{1}^{(\mathrm{u})}=\mathrm{z}_{1}^{(\mathrm{u})}$ & $\mathrm{v}_{2}^{(\mathrm{u})}=\mathrm{z}_{2}^{(\mathrm{u})}$ & $\overline{\mathrm{v}}^{(\mathrm{u})}=\overline{\mathrm{z}}^{(\mathrm{u})}$ \\
\hline 1 & 7.0 & 7.0 & 7.00 \\
2 & 8.4 & 8.7 & 8.55 \\
3 & 8.9 & 8.6 & 8.75 \\
4 & 11.3 & 11.0 & 11.15 \\
\hline 5 & 10.5 & 10.5 & 10.50 \\
6 & 7.4 & 7.0 & 7.20 \\
7 & 10.4 & 10.2 & 10.30 \\
8 & 7.8 & 7.6 & 7.70 \\
\hline 9 & 9.2 & 8.9 & 9.05 \\
10 & 9.1 & 8.95 & 9.03 \\
11 & 9.1 & 9.0 & 9.05 \\
12 & 9.1 & 8.95 & 9.03 \\
13 & 9.0 & 8.9 & 8.95 \\
\hline \multicolumn{4}{|c}{} \\
\hline
\end{tabular}

After calculations by means of the formulae (2), (3), (4) and $(5)$ the following results were obtained :

is variance of measured values of ship speed $\sigma^{2}(\mathrm{v})=0.0258$

is standard deviation of $\sigma(\mathrm{v})=0.16 \mathrm{knot}$

is standard deviation of the average value $\sigma_{\bar{z}}=0.032 \mathrm{knot}$

$\dot{*}$ variability coefficient of measured values $\sigma=1.8 \%$.

\section{ACCURACY ASSESSMENT OF ME FUEL CONSUMPTION MEASUREMENTS}

The accuracy assessment of fuel consumption measurements was performed for the results obtained in average sea conditions, presented in the table below:

\begin{tabular}{|c|c|c|c|}
\hline \multirow{2}{*}{$\begin{array}{c}\text { No. of } \\
\text { measurement }\end{array}$} & \multicolumn{3}{|c|}{ Fuel consumption per hour $\mathrm{B}_{\mathbf{h}}$ [kg/h] } \\
\cline { 2 - 4 } & Series no. 2 & Series no. 4 & On average \\
\hline $\mathrm{u}$ & $\mathrm{B}_{\mathrm{h} 1}^{(\mathrm{u})}=\mathrm{z}_{1}^{(\mathrm{u})}$ & $\mathrm{B}_{\mathrm{h} 2}^{(\mathrm{u})}=\mathrm{z}_{2}^{(\mathrm{u})}$ & $\overline{\mathrm{B}}_{\mathrm{h}}^{(\mathrm{u})}=\overline{\mathrm{Z}}^{(\mathrm{u})}$ \\
\hline 1 & 50.22 & 51.84 & 51.03 \\
2 & 75.27 & 83.66 & 79.47 \\
3 & 114.13 & 110.13 & 112.13 \\
4 & 183.57 & 182.09 & 182.83 \\
\hline 5 & 169.91 & 170.36 & 170.14 \\
6 & 52.04 & 55.44 & 53.74 \\
7 & 137.25 & 134.85 & 136.05 \\
8 & 74.02 & 74.31 & 74.17 \\
\hline 9 & 102.33 & 102.43 & 102.43 \\
10 & 101.20 & 101.25 & 101.23 \\
11 & 100.27 & 98.91 & 99.59 \\
12 & 101.20 & 101.25 & 101.23 \\
13 & 100.91 & 102.32 & 101.65 \\
\hline \multicolumn{4}{|c}{} \\
\hline
\end{tabular}

After calculations by means of the formulae (2), (3), (4) and (5) the following results were obtained :

variance of measured values of fuel consumption $\sigma^{2}\left(B_{b}\right)=4.33$

$>$ standard deviation of $\sigma\left(\mathrm{B}_{\mathrm{h}}\right)=2.1 \mathrm{~kg} / \mathrm{h}$

$>$ standard deviation of the average value $\sigma_{\overline{\mathrm{Z}}}=0.41 \mathrm{~kg} / \mathrm{h}$

$>$ variability coefficient of measured values $\sigma=2.0 \%$.

\section{ACCURACY ASSESSMENT OF THE MEASUREMENT METHOD FOR SHIP SPEED}

As the ship speed measurement is direct, its accuracy depends on accuracy of measuring instrument and external disturbances influencing the investigated object. The mean square error of measurement method is determined by using the relation (6). For a single measured quantity (ship speed v) it takes the form :

$$
\sigma(\mathrm{v})=\sqrt{\sigma^{2}(\mathrm{v})}
$$

hence it is equal to the square root from variance of the measured values :

$$
\sigma(v)=\sqrt{\frac{1}{r-1} \sum_{i=1}^{r}\left(v_{i}-\bar{v}\right)^{2}}
$$

$v_{i}$ - result of a single read-out of ship speed

$\overline{\mathrm{V}}^{\mathrm{i}}$ - average speed in a measurement point

$r$ - number of repetition in a measurement point.

To calculate the mean square error, were taken the measurement results at the $\mathrm{ME}$ rotational speed $\mathrm{n}=830 \mathrm{rpm}$ and propeller pitch $\mathrm{H}=80 \%$ for the sea conditions in centrum of measurement series 2 and 4, presented in the table below :

\begin{tabular}{|c|c|c|}
\hline No. & No. of measurement series & $\mathbf{v}[\mathbf{k n}]$ \\
\hline 1 & 2 & 9.2 \\
2 & & 9.1 \\
3 & 4 & 9.0 \\
\hline 4 & & 8.9 \\
5 & & 9.0 \\
6 & & 8.9 \\
\hline \multicolumn{2}{|c|}{ On average $\overline{\mathbf{v}}$} & 9.02 \\
\hline \multicolumn{2}{|c|}{ Number of repetitions $\mathrm{r}$} & 6 \\
\hline
\end{tabular}

After calculations by using the formulae (9) and (5) the following was obtained :

$\star$ the mean square error of the ship speed measurement method $\sigma(\mathrm{v})=0.12 \mathrm{kn}$

$\star$ variability coefficient of measurement results $\sigma=1.3 \%$.

\section{ACCURACY ASSESSMENT \\ OF THE MEASUREMENT METHOD FOR ME FUEL CONSUMPTION}

The ME hourly fuel consumption is the direct measurement function described by the formula :

$$
\mathrm{B}_{\mathrm{h}}=\frac{3600 \mathrm{~V} \rho_{\mathrm{t}}}{\tau} \quad[\mathrm{kg} / \mathrm{h}]
$$

$\mathrm{V}=11 \mathrm{dm}^{3}$ - volume of calibrating tank

$\rho_{t}=\rho_{15}-(t-15) 0.00064\left[\mathrm{~kg} / \mathrm{dm}^{3}\right]-$ fuel density in temperature of measurements

$\rho_{15}=0.875 \mathrm{~kg} / \mathrm{dm}^{3}-$ fuel density at $15^{\circ} \mathrm{C}$ (standard density) 
$\mathrm{t}\left[{ }^{\circ} \mathrm{C}\right]$ - temperature of fuel

$\tau[\mathrm{s}]-$ consumption time of fuel contained in calibrating tank volume.

After inserting constant values the formula takes the form :

$$
\mathrm{B}_{\mathrm{h}}=\frac{35030.6-25.34 \mathrm{t}}{\tau}[\mathrm{kg} / \mathrm{h}]
$$

The mean square error of the fuel consumption measurement method is calculated on the basis of the relation (7). In the case in question it is described as follows :

$$
\sigma\left(\mathrm{B}_{\mathrm{h}}\right)=\sqrt{\left(\frac{\partial \mathrm{B}_{\mathrm{h}}}{\partial \mathrm{t}}\right)^{2} \sigma^{2}(\mathrm{t})+\left(\frac{\partial \mathrm{B}_{\mathrm{h}}}{\partial \tau}\right)^{2} \sigma^{2}(\tau)}
$$

Values of the partial derivatives of the function (11), with respect to fuel temperature and measurement time, after inserting the average measured values (see the table below), are as follows, respectively :

$$
\begin{gathered}
\frac{\partial \mathrm{B}_{\mathrm{h}}}{\partial \mathrm{t}}=\frac{-25.34}{\tau}=-0.07542 \\
\frac{\partial \mathrm{B}_{\mathrm{h}}}{\partial \tau}=\frac{25.34 \mathrm{t}-35030.6}{\tau^{2}}=-0.3012
\end{gathered}
$$

The mean square error of fuel temperature measurements is equal to :

$$
\sigma(\mathrm{t})=\sqrt{\frac{1}{\mathrm{r}-1} \sum_{\mathrm{i}=1}^{\mathrm{r}}\left(\mathrm{t}_{\mathrm{i}}-\overline{\mathrm{t}}\right)^{2}}
$$

$t_{i}-$ result of a single read-out of fuel temperature

$\frac{1}{\mathrm{t}}$ - average result of fuel temperature measurement

$r$ - number of repetitions in a measurement point.

The mean square measurement error of consumption time of fuel contained in calibration tank volume is equal to :

$$
\sigma(\tau)=\sqrt{\frac{1}{r-1} \sum_{i=1}^{r}\left(\tau_{i}-\bar{\tau}\right)^{2}}
$$

where :

$\tau_{i}$ - result of a single read-out of consumption time of fuel contained in the calibrating tank volume

$\bar{\tau}$ - average consumption time of fuel contained in calibrating tank volume

\begin{tabular}{|c|c|c|c|c|c|}
\hline \multirow[b]{2}{*}{ No. } & \multirow{2}{*}{\begin{tabular}{|c|}
$\begin{array}{c}\text { No. of } \\
\text { measurement } \\
\text { series }\end{array}$ \\
\end{tabular}} & \multicolumn{2}{|c|}{$\tau$} & \multirow{2}{*}{$\frac{\mathbf{t}}{{ }^{\circ} \mathbf{C}}$} & \multirow{2}{*}{$\begin{array}{c}\mathrm{B}_{\mathrm{h}} \\
\mathrm{kg} / \mathrm{h}\end{array}$} \\
\hline & & $\min$ & sec & & \\
\hline 1 & \multirow{3}{*}{2} & 5 & 32.4 & 40 & 102.33 \\
\hline 2 & & 5 & 39.2 & 40 & 100.27 \\
\hline 3 & & 5 & 36.9 & 41 & 100.91 \\
\hline 4 & \multirow{3}{*}{4} & 5 & 31.8 & 40 & 102.52 \\
\hline 5 & & 5 & 43.6 & 40 & 98.91 \\
\hline 6 & & 5 & 32.2 & 41 & 102.32 \\
\hline & On average & 5 & 36.0 & 40.3 & 101.21 \\
\hline \multicolumn{3}{|c|}{ Average time $\bar{\tau}[\mathrm{s}]$} & 336.0 & & \\
\hline \multicolumn{3}{|c|}{ Number of repetitions $r$} & 6 & & \\
\hline
\end{tabular}

$\mathrm{r}$ - number of repetitions in a measurement point.

To determine the mean square error of fuel consumption the measurement results at the ME rotational speed $n=830 \mathrm{rpm}$ and propeller pitch $\mathrm{H}=80 \%$ for the sea conditions in centrum of 2 and 4 measurement series, presented in the table below, were applied :
After the calculations by using the formulae (12) and (5) the following was obtained:

次 the mean square error of the fuel consumption measurement method $\sigma\left(\mathrm{B}_{\mathrm{h}}\right)=1.44 \mathrm{~kg} / \mathrm{h}$

variability coefficient of results $\sigma=1.4 \%$.

\section{ACCURACY ASSESSMENT OF MEASUREMENTS OF SHIP PROPELLER SHAFT TORQUE}

Torque measurements were carried out with the use of special instruments installed by the measuring team. For the measurements was used the PHILIPS PR 9914/01-NC 9408499 strain-gauge torque meter with analogue read-out system.

Accuracy assessment of torque measurements was performed for the results obtained from two measurement series (no. 2 and 4 - according to the same notation as that used in the measurement reports from shipboard tests) carried out in similar conditions, presented in the table below :

\begin{tabular}{|c|c|c|c|}
\hline \multirow{2}{*}{$\begin{array}{c}\text { No. of } \\
\text { measurement }\end{array}$} & \multicolumn{3}{|c|}{ Torque M[Nm] } \\
\cline { 2 - 4 } & Series no. 2 & Series no. 4 & On average \\
\hline $\mathrm{u}$ & $\mathrm{M}_{1}^{(\mathrm{u})}=\mathrm{z}_{1}^{(\mathrm{u})}$ & $\mathrm{M}_{2}^{(\mathrm{u})}=\mathrm{z}_{2}^{(\mathrm{u})}$ & $\overline{\mathrm{M}}^{(\mathrm{u})}=\overline{\mathrm{z}}^{(\mathrm{u})}$ \\
\hline 1 & 3460 & 3332 & 3396 \\
2 & 5895 & 5831 & 5863 \\
3 & 6023 & 5575 & 5799 \\
4 & 10509 & 10317 & 10413 \\
\hline 5 & 8971 & 8715 & 8843 \\
6 & 3845 & 3909 & 3877 \\
7 & 8843 & 8843 & 8843 \\
8 & 4357 & 4229 & 4293 \\
\hline 9 & 6216 & 6216 & 6216 \\
10 & 6248 & 6184 & 6216 \\
11 & 6280 & 6151 & 6216 \\
12 & 6280 & 6087 & 6184 \\
13 & 6280 & 6023 & 6152 \\
\hline \multicolumn{4}{|c|}{} \\
\hline
\end{tabular}

After calculations by using the formulae (2), (3), (4) and (5) the following was obtained:

* variance of measured torque values $\sigma^{2}(\mathrm{M})=18003.8$

* standard deviation of $\sigma(\mathrm{M})=134.2 \mathrm{Nm}$

* standard deviation of the average value $\sigma_{\overline{\mathrm{z}}}=26.3 \mathrm{Nm}$

* variability coefficient of results $\sigma=2.1 \%$.

\section{USEFULNESS ASSESSMENT OF STANDARD INSTRUMENTS FOR ENERGY MEASUREMENTS}

The obtained results of the assessment of measurement accuracy, performed with the use of ship standard instrumentation, are contained within the interval of $2 \%$ variability coefficient, and the assessment of accuracy of measurement methods - of $1.5 \%$. It makes it possible to conclude that the standard measuring instruments are fully useful for carrying out energy measurements on ships.

The variability coefficient of measurement results obtained by means of the special instruments for torque measuring, amounts to $2.1 \%$, hence it is not greater than that in the case of the standard measuring instruments installed on ships. 
the accuracy of the measurement methods, which is higher than that of measurement results, confirms that the reasoning presented in this paper is correct.

Similar energy measurements were carried out in the laboratory of combustion engines of Ship Power Plant Department, Gdynia Maritime University. As expected, the obtained results were found even more accurate in view of the stable operational conditions and loading state of the laboratory engine. For instance the variability coefficient value of measurement results of hourly fuel consumption, equal to $0.65 \%$ was obtained.

To conclude one should state that the standard measurement instrumentation which is installed as a rule onboard contemporary ships, can be successfully used for energy measurements. In particular, the measurements performed with the use of the standard instrumentation are of the following features :

a sufficient accuracy

$\rightarrow$ no special instruments are required to be installed (a decrease of cost)

- they can be carried out by ship's crew itself hence no additional measuring team is required (a decrease of cost)

$\rightarrow$ measurement results may be used in operational and diagnostic analyses of technical state of ship's propulsion system.

\section{NOMENCLATURE}

$\mathrm{B}_{\mathrm{h}}[\mathrm{kg} / \mathrm{h}]$ - hourly fuel consumption

$\mathrm{H}[\%]$ - pitch of CP propeller (Controllable Pitch Propeller)

KBN - The State Committee for Scientific Research

$\mathrm{M}[\mathrm{Nm}]$ - torque

$\mathrm{n}[\mathrm{rpm}]$ - rotational speed

- number of measurement repetitions

$\mathrm{t}\left[{ }^{\circ} \mathrm{C}\right] \quad-$ temperature

$\mathrm{u} \quad$ - number of a measurement point

$\mathrm{v}[\mathrm{kn}] \quad$ - ship speed

$\mathrm{V}\left[\mathrm{dm}^{3}\right]$ - volume

$z_{j} \quad$ - result of a single measurement

$\bar{z}_{j} \quad$ - average value from a sample of measurement results

$\mathrm{z}_{\mathrm{j}}^{(\mathrm{u})} \quad$ - result of a single measurement point

$\mathrm{z}^{\text {(u) }} \quad-$ value in a measurement point

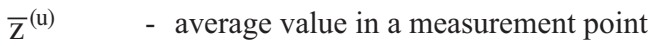

$\overline{\mathrm{Z}}_{\mathrm{sr}}^{(\mathrm{u})} \quad$ - average value from a sample of measurement results

$\delta_{\mathrm{m}} \quad$ - measurement method error

$\delta_{\mathrm{o}}^{\mathrm{m}} \quad$ - variability measure of an object

$\delta_{\mathrm{zw}} \quad-$ variability measure of results

$\rho\left[\mathrm{kg} / \mathrm{dm}^{3}\right]$ - density

$\sigma$ - relative mean square error

$\sigma^{2} \quad$ - variance

$\sigma(z) \quad-$ mean square error

$\sigma_{z} \quad$ - standard deviation of average value

$\tau[\mathrm{s}] \quad-$ time

\section{BIBLIOGRAPHY}

1. Adamkiewicz H.G.: Statistics, applications to economy (in Polish). The Centre for Personnel Advising and Improving Co (Ośrodek Doradztwa i Doskonalenia Kadr Sp. z o.o.). Gdańsk. 1996

2. Polański Z.: Planning experiments in engineering (in Polish). State Scientific Publishing House (Państwowe Wydawnictwo Naukowe). Warszawa. 1984

3. Strzałkowski A., Śliżyński A.: Mathematical methods for elaboration of measurement results (in Polish), State Scientific Publishing House (Państwowe Wydawnictwo Naukowe). Warszawa. 1969
4. Szydłowski H., Kaczmarek W., Kotłowska M., Kozak A., Kudyńska J.: Theory of measurements (in Polish). State Scientific Publishing House (Państwowe Wydawnictwo Naukowe). Warszawa. 1981

5. Taylor J.R.: Introduction to measurement error analysis (in Polish). Scientific Publishing House (Państwowe Wydawnictwo Naukowe PWN). Warszawa. 1999

6. Volk W.: Applied statistics for engineers (in Polish). Scientific -Technical Publishers (Wydawnictwo Naukowo - Techniczne). Warszawa. 1985

7. Górski Z.: A method to choose settings of the elements of ship main propulsion system fitted with controllable pitch propeller in the aspect of operational effectiveness of ship power plant (in Polish). Doctoral thesis under supervision of Prof. Romuald Cwilewicz. Mechanical Faculty, Gdynia Maritime University. Gdynia. 2003

\section{CONTACT WITH THE AUTHORS}

Zygmunt Górski, D.Sc., Eng. Assoc. Prof. Romuald Cwilewicz Faculty of Marine Engineering, Gdynia Maritime University Morska 81/87 81-225 Gdynia, POLAND e-mail : zyga@am.gdynia.pl

\section{Conference CYLINDER 2006}

On 26-28 September 2006 in Zakopane, Polish town at the foot of Tatra Mountains, was held 16th country-wide technical scientific conference on :

\section{Testing, construction, production and operation of hydraulic systems}

during which were presented 28 papers whose authors and co-authors were research workers from 13 scientific research centres and 5 industrial institutions. The largest share in realization of the Conference program (6 papers) was brought in by the authors representing KOMAG, the Centre for Mechanization of Mining in Gliwice. Foreign guests from the LUBRICANT, a Czech firm, presented one paper.

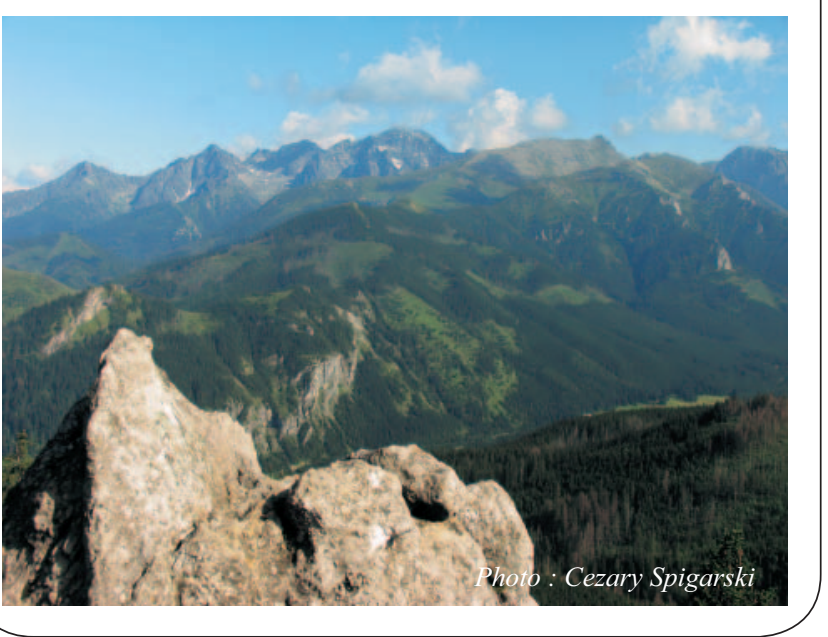

